\title{
Bir İnsansız Kara Aracı İçin Yüksek Verimli Fırçasız Doğru Akım Motoru Tasarımı
}

\author{
Ömer Cihan KIVANÇ*1 \\ ${ }^{1}$ İstanbul Okan Üniversitesi, Mühendislik Fakültesi, Elektrik-Elektronik Mühendisliği Bölümü, 34959, İstanbul, Türkiye
}

(ORCID: https://orcid.org/0000-0003-0880-134X)

(Alınış / Received: 19.12.2018, Kabul / Accepted: 17.06.2020, Online Yayınlanma / Published Online: 20.08.2020)

\author{
Anahtar Kelimeler \\ İnsansız kara aracı, \\ Fırçasız doğru akım motoru, \\ Sonlu elemanlar yöntemi, \\ Araç dinamiği, \\ Mekanum tekerlek, \\ İtki sistemleri
}

\begin{abstract}
Özet: İnsansız kara araçları (IKKA) sahip oldukları farklı modüller sebebiyle araştırmacılara çeşitli çalışma alanları sunmaktadır. Bu modüller sensör teknolojileri, gömülü sistemler, haritalandırma ve konumlama, yörünge takibi, mekanik tasarım, elektrik motoru ve batarya teknolojileri gibi alanlardan oluşabilmektedir. Bu araştırma alanlarından elektrik motoru teknolojisinde her ne kadar bahsedilen diğer alanlara göre daha fazla limit tasarım değerlerine ulaşılmış olsa da insansız araçların sahip oldukları karmaşık ve kendine özgü kısıtlar sebebiyle farklı tasarım yaklaşımlarına ihtiyaç duyulmaktadır. Yapılan çalışmada çok yönlü hareket kabiliyetli, düşük sürtünmeli ve yüksek titreşimli bir IKA için özel bir dış rotorlu fırçasız doğru akım motoru (FDAM) tasarlanmıştır. Yapılan tasarımda düşük hız, yüksek moment ve yüksek verimde bir FDAM'u kısıtlı alan ve hacim koşulları göz önünde bulundurularak kolay imal edilebilir bir yapıda geliştirilmiştir. Çalışmada analitik çözümler ANSYS RMxprt, 2 ve 3 boyutlu analizler ise sonlu elemanlar yöntemine (SEY) dayanan ANSYS Maxwell ile yapılmıştır. Elde edilen sonuçlar, başlangıç motivasyonu ile tasarım çıktıları arasındaki uygunluğu göstermiş ve üretilebilir bir elektrik motoru geliştirilmiştir.
\end{abstract}

\section{High Efficiency Brushless Direct Current Motor Design for an Unmanned Ground Vehicle}

\section{Keywords}

Unmanned ground vehicle, Brushless direct current motor, Finite element method, Vehicle dynamics, Mecanum wheels, Propulsion systems

\begin{abstract}
Unmanned ground vehicles (UGV) offer different study areas to researchers due to their various modules. These modules can be included sensor technologies, embedded systems, mapping and localization, trajectory tracking, mechanical design, electric motor and battery technologies. Although electric motor technology from these research areas has reached more limit design values than the other areas mentioned, different design approaches are needed due to the complex and specific constraints of unmanned vehicles. In this study, a special outer rotor brushless direct current motor (BLDC) has been designed for UGV which has multi-axis movement, low friction and high vibration. Low speed, high torque and high efficiency in the design of a BLDC is restricted to space and volume can be easily manufactured. In the study, analytical solutions by ANSYS RMxprt, 2 and 3 dimensional analyzes are performed based on finite element method (FEA) using ANSYS Maxwell. The results obtained show the validity between the initial motivation and the design outputs and an electric motor which is producible, has been developed.
\end{abstract}

\section{Giriş}

Son yıllarda akıllı ulaşım sistemleri alanında yapılan akademik çalışmaların odak noktalarının başında, insansız kara araçları (İKA) ve bileşenlerinin geliştirilmesi gelmektedir [1], [2]. İKA'lar insan desteği olmadan belirlenen bir taktik, görev ya da seyrüseferi gerçekleştirebilen otonom sistemler bütünü olarak tanımlanmaktadır [3]. Bu sistemler sadece bireysel kullanımlara yönelik olmadığg gibi endüstriyel ve askeri amaçlar için de kullanılabilmektedir [4], [5]. Bu uygulama alanları gerek mekanik gerekse de elektrik/elektronik bileşenlerin tasarım kısıt ve kıstaslarına doğrudan etki etmektedir. Özellikle itki sistemleri ve manevra kabiliyetleri mekanik tasarım sürecini belirlerken, çevresel tanıma ve karar verme kabiliyetleri ise sensör, gömülü sistem ve kontrol algoritmalarını tayin etmektedir [6]. Literatürde İKA çalışmaları çoğunlukla haritalandırma ve konumlama [7], yörünge takibi [8], sensör bütünleştirme ve teknolojilerine [9] yönelik olmakta, buna karşılık itki ve mekanik sistemler genellikle geleneksel araç tasarımı yaklaşımına göre geliştirilmektedir. Ancak İKA'lar sahip oldukları sıradışı geometri, dinamik etkenlerin fazlalığ 1 ve tolerans paylarının azlığ 1 sebebiyle daha 
karmaşık bir tahrik sistemine sahiptirler [10]. İKA'lar için geleneksel araç tasarım yaklaşımlarının yerine göreve göre eyleyici, tahrik ve tekerlek tipi seçilmektedir. Bilhassa dar alan çalışmaları, lojistik uygulamaları [11], havacılıkta ve askeri uygulamalarda [12], [3] çok yönlü doğrudan tahrikli tekerlekler tercih edilmektedir [13], [14]. Bu sistemlerin en önemli avantajı çok çekişli kontrol, direksiyondan bağımsız dönüş kabiliyeti ve farklı operasyonel görevlere hızlıca uyum sağlayabilmeleridir [15].

Yapılan çalışmada mekanum tekerleklere sahip bir İKA'nın güç, moment talebi ve mekanik sınırları dikkate alınarak dış rotorlu özel bir firçasız doğru akım motoru tasarlanmıştır. Şekil 1'de gösterilen İKA'da kullanılan mekanum tekerlekler $45^{\circ}$ 'lik farklarla birbirine paralel yerleştirilmiş ve bir seri mini silindir tekerleğin çemberin etrafına sarılmasından oluşmaktadır [16]. Çok eksenli hareket kabiliyetini kazandıran bu mini silindirler genellikle tekerlek düzlemi ve hareket ekseni ile $45^{\circ}$ 'lik açı yapacak şekilde konumlandırılmaktadır. Bu mini tekerlekler hem kullanılan malzeme hem de sahip oldukları geometri sebebiyle geleneksel tekerlekler kadar sürtünme kuvvetine maruz kalmazlar [12]. Sürtünme kuvveti değeri düşük olduğundan ötürü ivmelenme becerisi ya da mekanum tekerleklere özgü hareketlerin yüksek verimde gerçekleştirilmesi gerekmektedir. Ayrica mekanum tekerleklerin yapısından kaynaklanan kayma ve serbest dönüşler diğer bir tahrik sistemi problemi olarak görülmektedir [12], [16]. Bu ihtiyaçları karşılayabilmek ve dezavantajları giderebilmek için yüksek hassasiyetli moment ve frenleme kuvvetinin sağlanması gerekmektedir. Tasarlanan diş rotorlu firçasız doğru akım motoru ile ani moment değişimlerinde ortaya çıkabilecek problemler giderilirken düşük sürtünmeden kaynaklı verimsiz hız minimuma indirgenerek daha başarılı bir yörünge takibi yapılabilecektir [17].

Çalışmada İKA'nın dinamik modellenmesinin ardından talep edilen güç, moment ve hız değerleri elde edilmiştir. Elde edilen bu değerler ile Şekil 1'de yer alan İKA'nın fiziksel sınırları dikkate alınarak motor temel büyüklükleri belirlenmiştir. Literatürde yer alan doğrudan tahrikli FDAM tasarımları incelenerek seçilen 36/42 oluk/kutup yapısına göre tasarım başlangıç motivasyonu oluşturulmuştur [18], [19], [20], [21]. Temel plaka değer ve parametrelerinin belirlenmesinin ardından tasarım parametreleri ve kullanılacak malzemelerin seçimi detaylıca açıklanmış ve ANSYS RMxprt ile analitik çözümler gerçekleştirilmiştir. Tasarım moment, hız, doyma ve verim gibi başlıca çıktılar açısından değerlendirildikten sonra ANSYS Maxwell elektromanyetik analiz programına aktarılmış, iki ve üç boyutlu olarak analiz edilerek optimize edilmiştir.

\section{2. İnsansız Kara Aracının Dinamik Modellenmesi}

Motor tasarımı için gerekli olan başlangıç tasarım kriterleri ile güç, moment ve hız değerleri İKA'nın dinamik modelinin elde edilmesiyle ortaya çıkmaktadır [22]. Şekil 2'de $x$-yönünde hareket eden bir İKA'nın doğrusal eksende üzerine etkiyen kuvvetler gösterilmektedir. İKA'nın talep ettiği çekiş kuvvetini, $F_{K}$, elde etmek için yuvarlanma direnci kuvveti, $F_{Y D K}$, tırmanma kuvveti, $F_{T K}$, hava direnci kuvveti, $F_{H D K}$ ve ivmelenme kuvvetinin, $F_{A}$, bulunması gerekmektedir. İKA modeli oluşturulurken mekanum

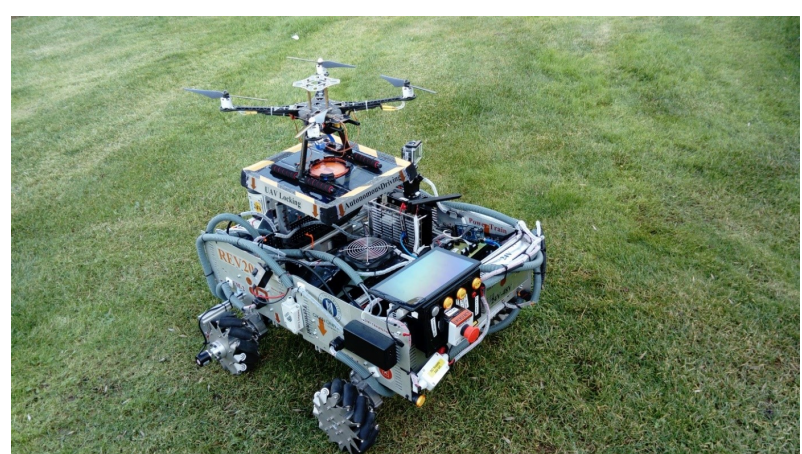

Şekil 1. Tahrik sistemi geliştirilen çok eksenli hareket edebilen insansız kara aracı.

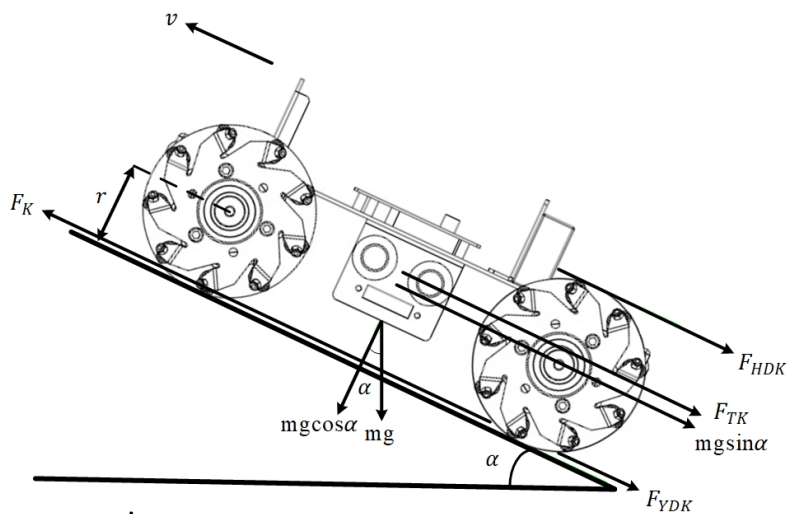

Şekil 2. İnsansız kara aracına etkiyen kuvvetlerin gösterimi.

tekerlekler silindirik olarak kabul edilmiş ve çekiş gücü kuvveti Denklem (1) kullanılarak elde edilmiştir.

$$
F_{K}=F_{Y D K}+F_{H D K}+F_{T K}+F_{A}
$$

Denklem (1)'de görülen $F_{H D K}$; İKA üzerinde hava sürtünmesi ile oluşan harekete ters yöndeki hava direnci kuvvetini göstermektedir. Denklem (2)'de bu kuvvetin bileşenleri gösterilmektedir.

$$
F_{H D K}=\frac{1}{2} \rho A_{f} C_{D} v^{2}
$$

Denklem (2)'de $A_{f}$, İKA'nın ön yüzey izdüşüm alanını, $\rho$, havanın kütlesel yoğunluğunu, $C_{D}$, aerodinamik sürüklenme katsayısını, $v$ ise İKA'nın doğrusal hızını göstermektedir. Denklem (3)'de ise yuvarlanma direnci kuvvetine ait ifade sunulmaktadır.

$$
F_{Y D K}=f_{r} m g
$$

Denklemde yer alan $f_{r}$, mekanum tekerleklerin silindir malzemesine ve dolgu oranına bağlı bir katsayı olarak kullanılmaktadır. Tekerlek yuvarlanma direnci; İKA'nın her bir tekerleğinde ki normal yük, tekerlek ile yol arasında ki sürtünme katsayısı ile çarpılarak hesaplanmaktadır. İKA'nın tırmanma kuvveti ise İKA ağırlığının eğim doğrultusunda ki bileşenine eşit olmaktadır. Hareketin yokuş aşağı olması durumunda bu bileşen negatif değer almaktadir.

$$
\begin{gathered}
F_{T K}=m g \sin \alpha \\
F_{A}=m a
\end{gathered}
$$


Denklem (4)'de tırmanma kuvvetine ait ifade gösterilmektedir. Hız değişimi durumunda, İKA ivmelenmek için ekstra kuvvete ihtiyaç duymaktadır. Bu kuvvete ait ifade Denklem (1)'de $F_{A}$ ile gösterilmekte ve hesaplanma biçimi ise Denklem (5)'de sunulmaktadır. Tablo 1'de İKA'nın güç ve moment talebini elde etmek için kurulan modelde kullanılan parametreler gösterilmektedir.

Tablo 1. İnsansız kara aracının dinamik eşitliklerinde kullanılan parametreler.

\begin{tabular}{cc}
\hline Parametre & Değer \\
\hline IKA ağırlığı $(\mathrm{m})$ & $100 \mathrm{~kg}$ \\
Tekerlek yarıçapı $(\mathrm{r})$ & $161.5 \mathrm{~mm}$ \\
IKA ön yüzey alan $\left(A_{f}\right)$ & $0.35 \mathrm{~m}^{2}$ \\
Yuvarlanma direnç katsayısı $\left(f_{r}\right)$ & 0.00025 \\
Aerodinamik direnç katsayısı $\left(C_{D}\right)$ & 0.01 \\
Yerçekimi ivmesi $(\mathrm{g})$ & $9.81 \mathrm{~m} / \mathrm{s}^{2}$ \\
Hava yoğunluğu $(\rho)$ & $1.2754 \mathrm{~kg} / \mathrm{m}^{3}$ \\
Maksimum eğim $(\alpha)$ & $20^{\circ}$ \\
\hline
\end{tabular}

Tablo 1'de verilen İKA özellikleri dikkate alınarak yapılan hesaplamaların sonucunda toplam 36.8 Nm'lik bir momente ihtiyaç duyulduğu ortaya çıkmıştır. İKA'nın 3 $\mathrm{km} / \mathrm{sa}$ 'lik maksimum hıza erişeceği düşünülerek ihtiyaç duyulan güç belirlenmiştir. Hesaplanan değerler dört motorun toplamına eşit olup her bir motorun sahip olması gereken güç ve moment değeri elde edilmiştir. Elektrik motorunun dişli kullanılmadan doğrudan tahrikli tasarlanacağı düşünüldüğünde, sahip olması gereken devir sayısı ise 207 dev/d (maksimum $3 \mathrm{~km} / \mathrm{sa}$ ) olarak belirlenmiştir. Hesaplanan nominal moment ve hız değerlerinin sağlanabilmesi için ihtiyaç duyulan güç aralığı 650-750 W olarak bulunmuştur. Ani ivmelenmeler, mekanum tekerleğe özgü ek güç ihtiyacı ve kayıplar dikkate alındığında $800 \mathrm{~W}$ gücün yeterli olacağı öngörülmüştür. Bu durumda her bir tekerlek için ayrı tasarlanacak elektrik motorunun gücü $200 \mathrm{~W}$ olarak hesaplanmıştır. Bu değerler ile motorun başlangıç tasarım değerleri elde edilmiş ve Tablo 2'de sunulmuştur.

Tablo 2. FDAM başlangıç tasarım değerleri.

\begin{tabular}{cc}
\hline Parametre & Değer \\
\hline Nominal güç & $200 \mathrm{~W}$ \\
Nominal hız & $207 \mathrm{dev} / \mathrm{d}$ \\
Maksimum rotor çapı & $176 \mathrm{~mm}$ \\
Nominal moment & $9.2 \mathrm{Nm}$ \\
\hline
\end{tabular}

\section{Tasarım Yaklaşımı ve Analiz Sonuçları}

Motor boyutlarının belirlenmesinde başlangıç yaklaşımında motor gücü referans alınmaktadır [23]. Tasarım sürecinde takip edilen akış Şekil 3'de gösterilmektedir. Motor tasarım optimizasyonunda ana hedef olarak diş etkisi momentinin minimuma indirilmesi, çıkış momentinde ki dalgalılı̆̆ın azaltılması, yüksek verim elde edilmesi ve optimum doyma değerlerine erişilmesi amacıyla farklı yapılarda ki kutup ayağı, oluk geometrileri için analiz çalışmaları yürütülmüştür. Buna ek olarak farklı kutup/oluk sayısı ve mıknatısların şekli ve yerleşimi ile ilgili farklı modeller benzetim programında koşturularak en ideal tasarım elde edilmiştir. Tasarlanacak motorun moment

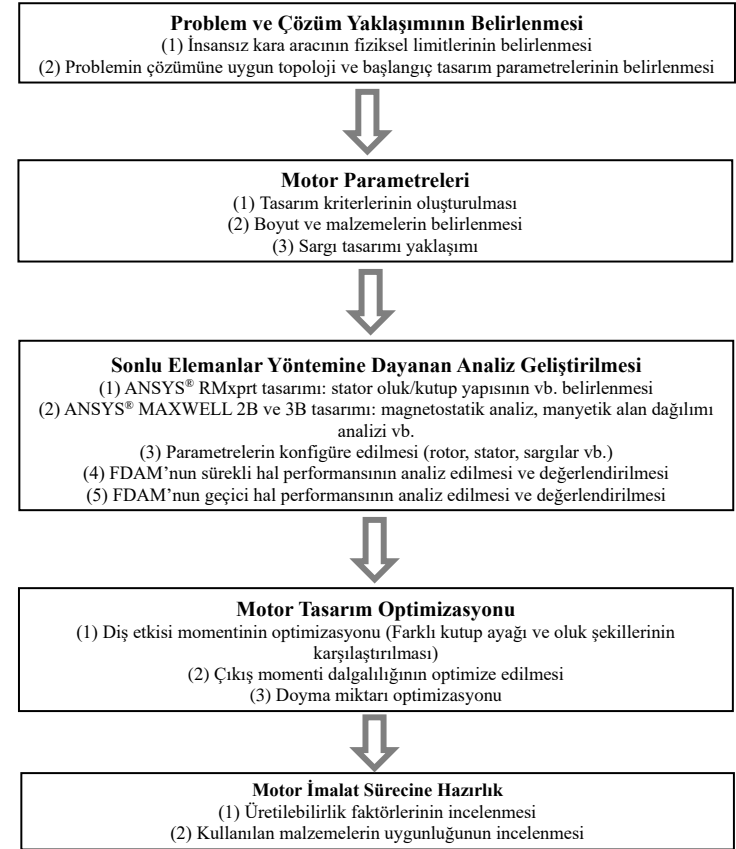

Şekil 3. Motor tasarım yaklaşımı.

ihtiyacı rotor çap1, rotor eksenel uzunluğu ile doğrudan ilişkilidir. Moment ifadesi rotor boyutlarına bağlı olup TRV (moment üretme kapasitesi), moment, güç ve hacim ilişkisinin belirlenmesinde önemli rol oynamaktadır [24]. Literatürde yer alan değerler incelendiğinde yüksek performanslı motorlarda motor tasarımında kullanılan $\mathrm{K}$ sabitinin, $11.8-39 \mathrm{kNm} / \mathrm{m}^{3}, K_{T R V}$ 'nin ise $15-50 \mathrm{kNm} / \mathrm{m}^{3}$ arasında olduğu görülmektedir [24]. Üretilecek momentin hesaplanması için kullanılan ifade Denklem (6)'da gösterilmektedir [24], [25].

$$
\begin{gathered}
T=K D_{r}{ }^{2} L_{r} \\
K_{T R V}=\frac{2 N B_{g} N i}{\pi D_{r}}
\end{gathered}
$$

Denklem (6) ve (7)'de $D_{r}, L_{r}, N, B_{g}, N i$ sirasiyla rotor çap1, rotor eksenel uzunluğu, sarım sayısı, hava aralığı akı yoğunluğu ve amper-sarımı ifade etmektedir. Tasarımda ki diğer bir faktörde, rotor dış çapı ve iç çapının belirlenmesinde hava aralığı uzunluğu, mıknatıs sırt demiri kalınlığı ve moment katsayısını sağlayacak uygun kalınlıktaki mıknatısların seçimidir. Yapılan tasarımda ise mekanum tekerleklerin çapı ve genişliği referans alınarak Denklem (1)'e uygun stator ve rotor uzunlukları belirlenmiştir. Stator iç çapı ise yapılan tasarım optimizasyonlarına bağlı olarak stator boyunduruğuna ve oluk yüksekliklerine bağglı olarak belirlenmiştir. Stator boyunduruk ve oluk yükseklik, genişlikleri ise analizler sonucu elde edilen akı yoğunluklarına göre optimize edilmiştir. Rotor dış çap1 ve iç çap1 ise hava aralığı, mıknatıs kalınlığı ve mıknatıslar arası izolasyon miktarına bağlı olarak belirlenmiştir. Hava aralığının belirlenmesinde ise aracın titreşimli bir alanda çalışacağ 1 göz önünde bulundurulmuştur. Bu sebeple 1 mm'nin altına inilmemiş ve $1 \mathrm{~mm}$ olarak seçilmiştir. Motor tasarımında kullanılan fiziksel büyüklükler Tablo 3'de gösterilmektedir. 
Tablo 3. Tasarlanan motorun fiziksel büyüklükleri.

\begin{tabular}{cc}
\hline Parametre & Değer \\
\hline Stator dış çapı & $159 \mathrm{~mm}$ \\
Stator iç çapı & $100 \mathrm{~mm}$ \\
Rotor uzunluğu $\left(L_{r}\right)$ & $40 \mathrm{~mm}$ \\
Hava aralığ 1 & $1 \mathrm{~mm}$ \\
Rotor dış çapı $\left(D_{r}\right)$ & $176 \mathrm{~mm}$ \\
Rotor malzemesi & Çelik \\
Miknatıs kalınlığ & $3 \mathrm{~mm}$ \\
Mıknatıs genişliği & $9.14 \mathrm{~mm}$ \\
Mıknatıs tipi & NdFe35 \\
\hline
\end{tabular}

Tasarımda dağıtılmış sargı yerine konsantrik sarg1 yapısı kullanılmıştır. Bu yapının seçilmesinde ana amaç, moment üretme kapasitesini arttırmak ve moment dalgalılı̆̆ını minimuma indirmektir. Ayrıca düşük hız/yüksek moment uygulamalarında karşılaşılan bakır kayıplarının minimuma indirilebilmesi için konsantrik sargı tercih edilmiştir. Seçilen 36/42 oluk/kutup yapısı kesirli oluk sargılı firçasız doğru akım motorlarında kullanılan bir konfigürasyon olup, 24/26 ve 18/20 oluk/kutup yapısı konfigürasyonları ile Tablo 4'de karşılaştırılmıştır. Seçimi yapılan 36/42 oluk/kutup yapısı akı dağılımının ve moment yoğunluğunun optimum olduğu yapı olarak belirlenmiş ve İKA için en uygun motor yapısı olduğu kanaatine varılmıştır.

Tablo 4. Farklı oluk/kutup kombinasyonlarının analiz sonuçları.

\begin{tabular}{cccc}
\hline Oluk/Kutup & $18 / 20$ & $24 / 26$ & $36 / 42$ \\
\hline Diş etkisi momenti (Nm) & 0.0023 & 0.0011 & 0.0042 \\
Verim (\%) & 82.63 & 84.32 & 87.15 \\
Ağırlık (kg) & 5.63 & 5.18 & 3.89 \\
\hline
\end{tabular}

Rotor sırt demirinin seçiminde manyetik geçirgenliğinin yüksek bir malzemeden olması sebebiyle 1010 çelik tercih edilmiştir. Statorda ise yüksek kaliteli sac malzeme seçilmiştir. Bunun amacı manyetik geçirgenliğin yüksek olmasını sağlamaktır. Bu sebeple M3629G tipi sac malzeme tercih edilmiştir. Mıknatıslar ise yüksek akı yoğunluğu sağlayabilen, sıcaklığa ve yüklenmeye karşı dayanımı yüksek NdFe35 tipi seçilmiştir [23]. Fırçasız doğru akım motorunun Şekil 1'de yer alan tekerlekler için tasarlandığ1 düşünüldüğünde stator dış çap1 $159 \mathrm{~mm}$, stator iç çapı $100 \mathrm{~mm}$, rotor uzunluğu $40 \mathrm{~mm}$, rotor diş çapı $176 \mathrm{~mm}$, mıknatıs kalınlığı $3 \mathrm{~mm}$ ve mıknatıs genişliği $9.14 \mathrm{~mm}$ olarak belirlenmiştir. Yapılan tasarımda hava aralığı uzunluğu, akının maksimum olmasını sağlayacak şekilde minimum seçilmiştir. Hava aralığı uzunluğu Denklem (6)'da görülen K değeri ile doğrudan ilişkilidir [24]. Diğ er bir ifadeyle, motorda hava aralığı arttıkça manyetik alan azalır ve motor istenen momenti veremez. Ayrica bu durumda motorun boşta çalışma hızı da artmaktadır. Hava aralığının belirlenmesinde ki ikinci faktör ise mekanik kısıtlardır. Özellikle motor hızının çok arttı̆̆ , çapın büyüdüğü ve titreşimli ortamlarda çalışan motorlarda $1 \mathrm{~mm}$ değerinin altına düşülmemesi gerekmektedir [26]. Özellikle mekanum tekerleklerin sahip olduğu titreşim oldukça yüksek değerlere erişmektedir. Bu sebeple hava aralığı seçimi önem arz etmektedir. Yapılan tasarım da hava aralığı değeri $1 \mathrm{~mm}$ olarak belirlenmiştir. Tasarımda performansı belirleyen bir diğer kriter ise tel çapı ve sarım sayısının belirlenmesidir [27]. Denklem (8)'de tel çapının belirlenmesinde kullanılan ifadeye yer verilmektedir.

$$
D_{t}=\sqrt{\frac{A_{s} F_{s}}{N}}
$$

Denklem (8)'de $D_{t}, A_{s}, F_{s}$ sirasıyla tel çapını, oluk kesit alanını ve stator oluk doluluk oranını belirtmektedir. Belirlenen oluk kesit alanı ve doluluk oranına göre farklı oluk tiplerini kullanmak mümkün olmaktadır. Ancak oluk doluluk oranının belirlenmesinde imalat koşulları göz önünde bulundurulmalı ve akım yoğunlukları, iletken kesiti, oluk diş kalınlığı ve oluk yüksekliği bu değere göre belirlenmelidir [21]. Tasarımda ise stator akım yoğunluğunun 6 $\mathrm{A} / \mathrm{mm}^{2}$ değerini geçmemesi hedeflenmiştir [25]. Ayrıca tasarımda mekanik kısıtlar hayli büyük etken olduğu için ve sargılarda meydana gelecek taşmayı önlemek için optimum iletken kesiti ve sarım sayısı kullanılarak oluk doluluk oranı \%60'ın altında tutulmuştur [21]. Yapılan tasarımda stator oluk doluluk oran $1 \% 57.84$ olarak ayarlanmış ve her bir olukta 37 iletkene müsaade edilmiştir. İletkenlerin çapı ise $0.912 \mathrm{~mm}$ olarak belirlenmiştir. Şekil 4 ve 5 'de sirasiyla motor stator ve rotor yapısı ile sarg1 bağlantı şeması gösterilmektedir.

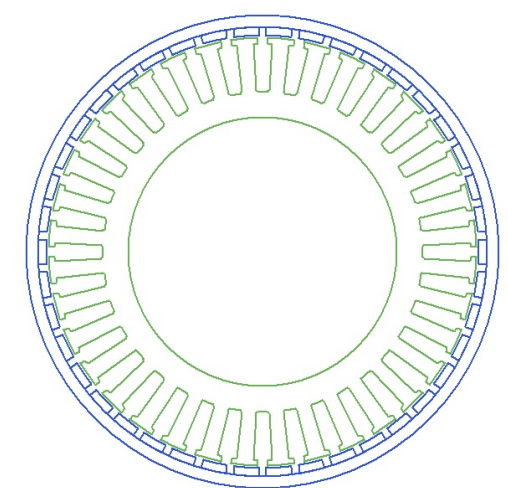

Şekil 4. Rotor ve statorun gösterimi.

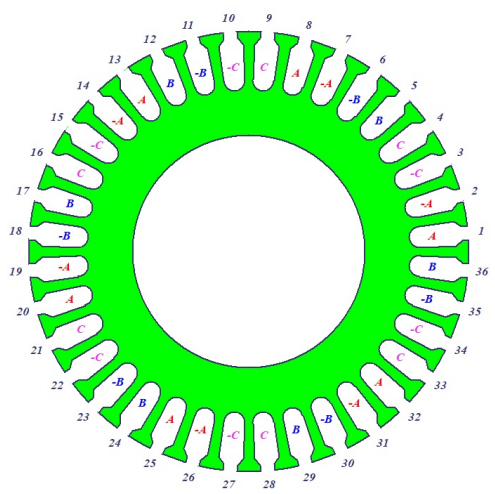

Şekil 5. Sargı şemasının gösterimi.

Çalışmanın ana motivasyonlarından birini oluşturan verim değeri farklı tasarım kombinasyonları denenerek elde edilmiştir. Tasarımda verimi arttırabilmek için bakır kayıplarının minimum tutulması gerekmektedir. Bakır kayıplarının belirlenmesinde direnç değeri önemli rol oynamakta ve bakır kayıplarını minimuma indirmenin yolu ise 
mümkün olan en kalın teli kullanmakla sağlanabilmektedir. Dolayısıyla tel çapının artışıyla akım yoğunluğu azalmaktadır. Denklem (9) ve (10)'da direnç değerini, $R$, ve akım yoğunluğunu, $J$, belirlemek için kullanılan eşitlikler gösterilmektedir.

$$
\begin{aligned}
& R=\frac{\rho L_{r} N}{\frac{\pi}{4} D_{t}{ }^{2}} \\
& J=\frac{I}{\frac{\pi}{4} D_{t}{ }^{2}}
\end{aligned}
$$

Denklem (9)'da $\rho$ bakırın öz direncini ifade etmektedir. Tasarlanan motorun terminal direnç değeri $0.37 \Omega$, akım yoğunluğu ise $3.89 \mathrm{~A} / \mathrm{mm}^{2}$ olarak elde edilmiştir. Denklem (11) ve (12)'de gösterilen kesirli kutup oluklu motorlarda endüklenen gerilim ifadesinde, $N_{f}$, bir fazdaki sarım sayısı, $f_{s}$, stator alanı frekansını, $k_{w}$, sargı faktörünü, $\phi$ ise mıknatıslardan kaynaklı temel hava aralığı akısını göstermektedir [25]. Denklem (11)'de de görüldüğü gibi endüktans ve endüklenen gerilim üzerinde akım yoğunluğunun etkisi bulunmamakta ve sarım sayısı ile değişim göstermektedir.

$$
E=2 \pi \frac{f_{s} N_{f} k_{w} \phi}{\sqrt{2}}
$$

Denklem (12)'de hesaplanan stator endüktans değeri, $L_{s}$ ise havanın geçirgenlik katsayısı, $\mu_{0}$, motorun eksenel uzunluğu, $L_{r}$, oluk genişliği, $b_{s}$, ve stator oluk derinliğine, $h_{s 2}$, bağlı değişmektedir. Endüktans üzerinde en büyük etken ise sarım sayısıdır, $N$, ve endüktans, sarım sayısının karesiyle orantilidir.

$$
L_{s}=\frac{\mu_{0} h_{s 2} L_{r} 4 N^{2}}{3 b_{s}}
$$

Tablo 5. Tasarlanan motorun özellikleri.

\begin{tabular}{cc}
\hline Parametre & Değer \\
\hline Nominal güç & $200 \mathrm{~W}$ \\
Nominal gerilim & $48 \mathrm{~V}$ \\
Oluk/kutup sayısı & $36 / 42$ \\
Oluk doluluk oranı & $\% 57.84$ \\
A ğırlık & $3.89 \mathrm{~kg}$ \\
Direnç & $0.37 \Omega$ \\
Endüktans & $2.1 \mathrm{mH}$ \\
$B_{\text {dis }}$ & $1.03 \mathrm{~T}$ \\
$B_{\text {stator }}$ & $0.32 \mathrm{~T}$ \\
$B_{\text {rotor }}$ & $0.88 \mathrm{~T}$ \\
$k_{e}$ & $1.71 V_{s} / \mathrm{rad}$ \\
$k_{t}$ & $1.92 \mathrm{Nm} / \mathrm{A}$ \\
Diş etkisi momenti & $0.0041 \mathrm{Nm}$ \\
Faz akımı & $4.78 \mathrm{~A}$ \\
Akım yoğunluğu & $3.89 \mathrm{~A} / \mathrm{mm}^{2}$ \\
Verim & $\% 87.15$ \\
Nominal hız & $208 \mathrm{dev} / \mathrm{d}$ \\
Boşta hız & $269 \mathrm{dev} / \mathrm{d}$ \\
Nominal moment & $9.17 \mathrm{Nm}$ \\
Maksimum moment & $108.6 \mathrm{Nm}$ \\
\hline
\end{tabular}

Fırçasız doğru akım motorlarında bakır, demir kayıpları doğru geometrinin belirlenmesi ve uygun malzeme seçimi ile küçültülebilmektedir ancak motor gücünün azalması ile kayıplarda aynı oranda azalmamaktadır. Bu oran literatürde ölçekleme faktörü ile ifade edilmektedir [25]. Bu sebeple küçük güçlü motorlarda kayıplar sebebiyle verimin çok yüksek değerlere ulaşmasının zor olduğu görülmektedir. İKA için tasarlanan motorun yüksek moment gereksinimine ihtiyaç duyması ve düşük güçlü olması sebebiyle baskın olan bakır kayıpları motorun çok yüksek verimlere ulaşamayacağının göstergesidir. Ancak tasarım için tercih edilen yüksek kutup sayılı motorda, istenilen momentin sağlanması için oluklarda daha az sargının bulunması gerekmektedir [20]. Kutup sayısının yüksek olması sebebiyle bakır ve demir ağırlıklarının azaltılması amaçlanmıştır. Ayrıca sarım sayısının azaltılması ile direnç ve endüktans değerinin azaltılması sağlanmış ve direnç değerinin azaltılmasıyla mümkün olan en yüksek verim değeri elde edilmiştir. Yapılan tasarımlar sonucunda verim değeri \%87.15 olarak elde edilmiştir. Tasarlanan motorun hız-verim eğrisi Şekil 6'da gösterilmiştir. Ayrıca tasarlanan motorun önemli özelliklerine Tablo 5'de yer verilmiştir.

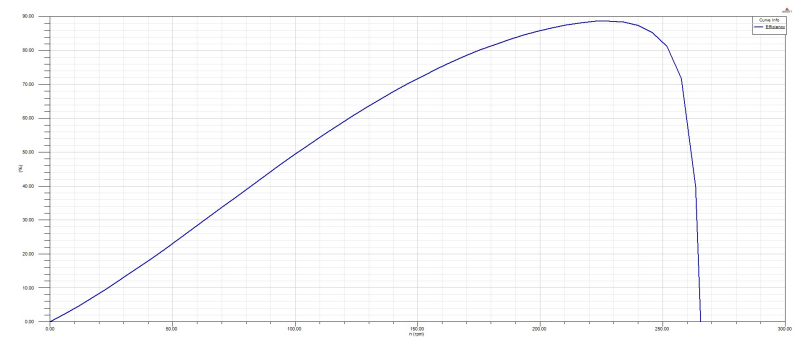

Şekil 6. Tasarlanan motorun hı-verim eğrisi.

Tasarım yaklaşımında diş etkisi momenti ve moment dalgalılığın kabul edilebilir düzeyde olmasına, motorun simetrik olmasına, stator çeliği ve rotor mıknatısı arasındaki etkileşimden doğan net radyal kuvvetin düşük olmasına dikkat edilmiştir. Ek olarak yüksek performanslı bir tasarım için sargı faktörü temel bileşeni yüksek değerde tutulmuştur. Aksi durumda motorda 1sınma, ek kayıp ve titreşimler meydana gelebilmektedir. Şekil 7'de RMxprt analizi sonucu elde edilen diş etkisi momenti grafiği verilmiştir. Analiz sonucu $0.00417 \mathrm{Nm}$ ortalama değerinde bir diş etkisi momenti hesaplanmıştır.

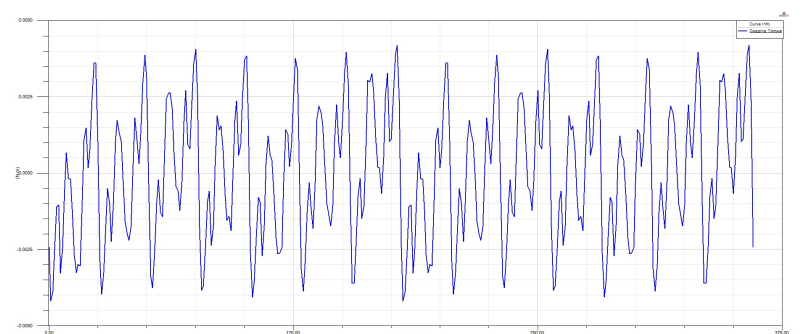

Şekil 7. Diş etkisi momenti grafiği.

Analitik tasarımları tamamlanan motorun iki ve üç boyutlu analizleri ANSYS Maxwell programı ile gerçekleştirilmiştir. Şekil 8 ve 9'da tasarlanan motorun sırasıyla iki boyutlu ve üç boyutlu analiz görünümü sunulmaktadır. Şekil 10'da gösterilen manyetik ak1 çizgilerinin stator dişleri ve sırt demirinde düzgün bir dağılım gösterdiği görülmektedir. İki boyut analizleri sonucunda tasarlanan motorun ak1 yoğunluğu dağılımı Şekil 11'de gösterilmektedir. Maksimum akı yoğunluğu belirli noktalarda $2.25 \mathrm{~T}$ 


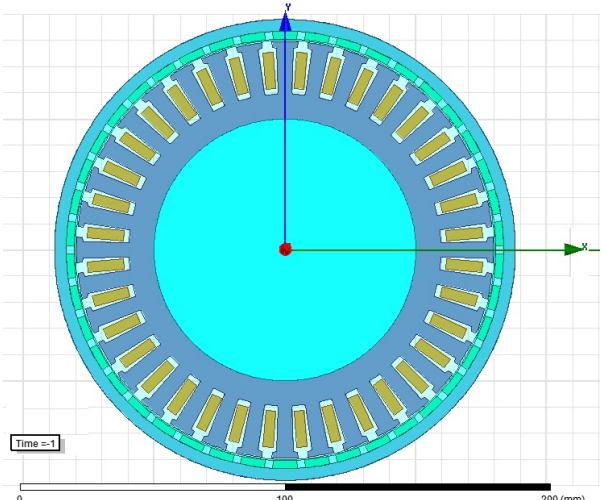

Şekil 8. İki boyutlu tasarım görünümü.

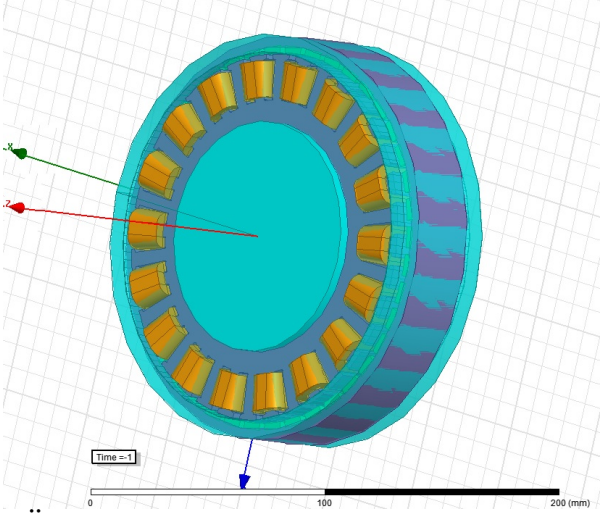

Şekil 9. Üç boyutlu tasarım görünümü.

olarak hesaplanmıştır.

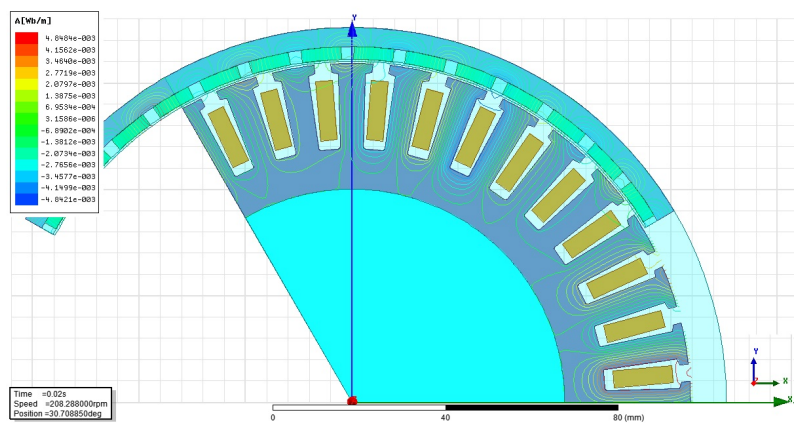

Şekil 10. Manyetik akı çizgilerinin gösterimi.

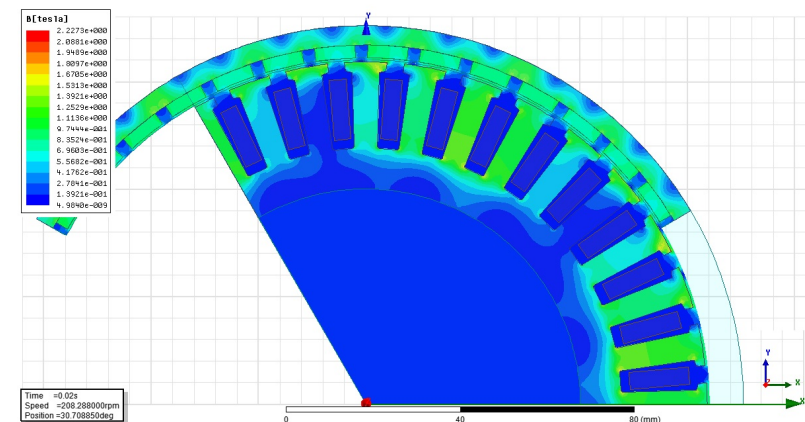

Şekil 11. Akım yoğunluğu dağılımının gösterimi.

Üç boyutlu analizlerin koşturulması sonucu elde edilen faz akım ve moment değerleri analitik hesaplamalarda elde edilen ortalama değerler ile uyuşmaktadır. Tasarlanan motorun faz akımları ve moment değeri grafikleri Şekil 12 ve
13 'te sunulmuştur. Akım değeri ve dalga formu istenilen düzeyde ve düzgün olarak elde edilmiştir. Momentte ki dalgalılığın oranı ise kabul edilebilir düzeyde ve düzgündür. Şekil 14'te tasarlanan motorun üç boyut manyetik ak1 dağılımı incelendiğinde, manyetik akı dağılımının sınır değerleri aşmayan bir analiz sonucuna sahip olduğu, sadece stator diş uçlarında sınır değere yaklaştığı ve $2.25 \mathrm{~T}$ civarında olduğu görülmektedir. Manyetik akı yoğunluğu stator boyunduruğunda 0.5-0.6 T, dişlerin en dar kısmında $1.7 \mathrm{~T}$ ve diş ortasında $1.5-1.7 \mathrm{~T}$ civarında tutulmuştur. Motor dişlerinin boyutları bu değerleri optimize edecek şekilde iteratif tasarım yaklaşımıyla düzenlenmiştir.

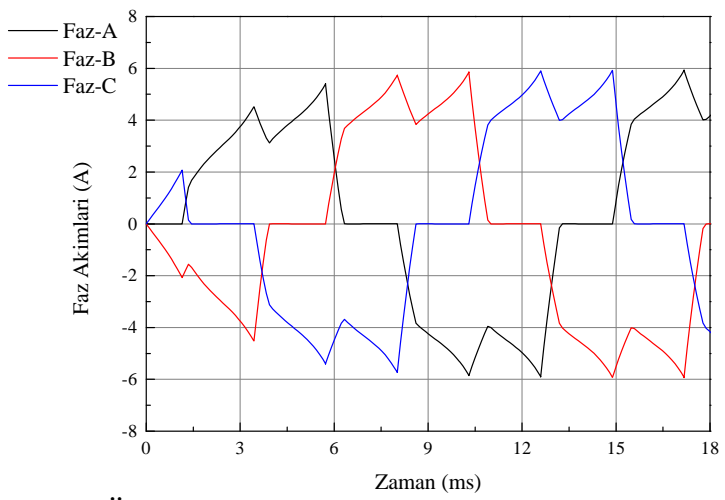

Şekil 12. Üç boyutlu analiz sonucu elde edilen faz akımları.

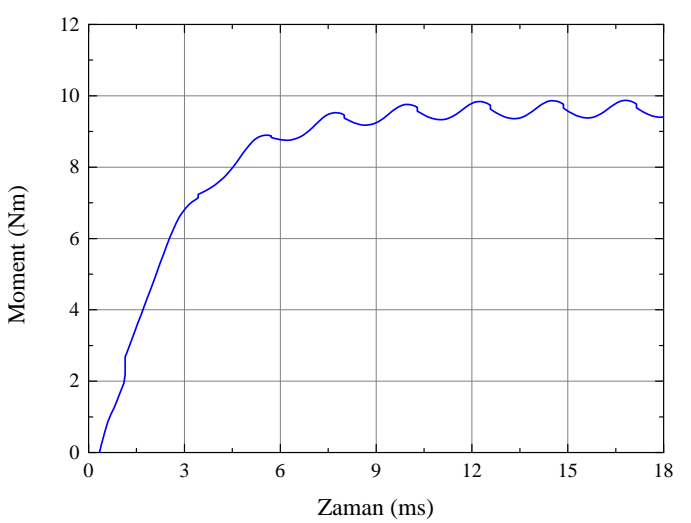

Şekil 13. Üç boyutlu analiz sonucu elde edilen moment grafiği.

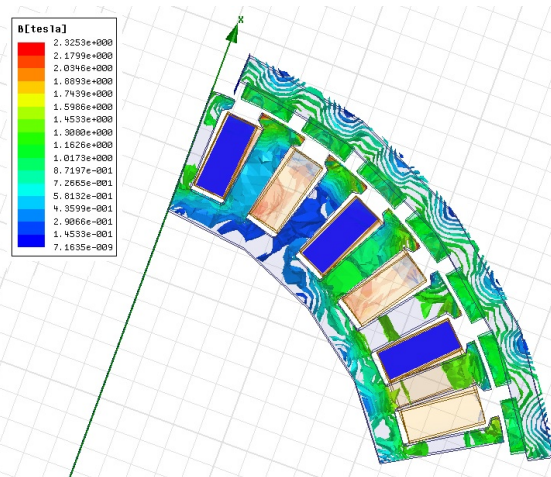

Şekil 14. Üç boyutlu analiz sonucu elde edilen manyetik alan dağılımının gösterimi. 


\section{Tartışma ve Sonuç}

Yapılan çalışmada bir insansız kara aracına özel dış rotorlu fırçasız doğru akım motoru tasarlanmıştır. Aracın mekanik kısıtları ve yüksek titreşime sahip yapısı sebebiyle hava aralığ $\breve{1}_{1}$ geniş tutularak elde edilebilecek maksimum verim sağlanmıştır. Seçilen 36/42 oluk/kutup sayısının optimum tasarım için doğru bir seçim olduğu anlaşılmış ve yapılan iki, üç boyutlu sonlu elemanlar analizi ile doymanın kabul edilebilir düzeyde olduğu gösterilmektedir. İKA'nın dinamik modelinin oluşturulması ile ortaya çıkan güç (200 W), moment $(9.17 \mathrm{Nm})$ ve hiz (208 dev/d) değerlerine tasarlanan motor \%87.15 verim değeri ile erişmiştir. Çalışmanın bir sonraki aşamasında tasarımı tamamlanan motorun imal edilerek İKA'ya montajının gerçekleştirilmesi ve İKA'nın mekanum tekerleklerinden kaynaklanan kayma, düşük sürtünme, verimsiz hız gibi dezavantajlarının önüne geçilmesi hedeflenmektedir.

\section{Kaynakça}

[1] Huang, W., Wen, D., Geng, J., Zheng, N. N. 2014. Task-Specific Performance Evaluation of UGVs: Case Studies at the IVFC. IEEE Transactions on Intelligent Transportation Systems, 15(2014), 1969-1979.

[2] Lam, A. Y. S., Yu, J. J. Q., Hou, Y., Li, V. O. K. 2017. Coordinated Autonomous Vehicle Parking for Vehicle-to-Grid Services: Formulation and Distributed Algorithm. IEEE Transactions on Smart Grid, 9(2017), 4356-4366.

[3] Young, S. H., Mazzuchi, T. A., Sarkani, S. 2017. A Framework for Predicting Future System Performance in Autonomous Unmanned Ground Vehicles. IEEE Transactions on Systems, Man, and Cybernetics: Systems, 47(2017), 1192-1206.

[4] Dickmanns, E. D. 2017. Developing the Sense of Vision for Autonomous Road Vehicles at UniBwM. Computer, 50(2017), 24-31.

[5] Pietras, B. 2015. New frontiers in driverless vehicles. Engineering \& Technology, 10(2015), 64-67.

[6] Touchton, B., Galluzo, T., Kent, D., Crane, C. 2016. Perception and Planning Architecture for Autonomous Ground Vehicles. Computer, 39(2006), 40-47.

[7] Bresson, G., Alsayed, Z., Yu, L., Glaser, S. 2017. Simultaneous Localization and Mapping: A Survey of Current Trends in Autonomous Driving. IEEE Transactions on Intelligent Vehicles, 2(2017), 194-220.

[8] Liu, J., Han, W., Liu, C., Peng, H. 2018. A New Method for the Optimal Control Problem of Path Planning for Unmanned Ground Systems. IEEE Access, 6(2018), 33251-33260.

[9] Silva, O.D., Mann, G. K. I., Gosine, R. G. 2015. An Ultrasonic and Vision-Based Relative Positioning Sensor for Multirobot Localization. IEEE Sensors Journal, 15(2015), 1716-1726.

[10] Kolakowska, E., Smith, S. F., Kristiansen, M. 2014. Constraint Optimization Model of a Scheduling Problem for a Robotic Arm in Automatic Systems.
Robotics and Autonomous Systems, 62(2014), $267-$ 280.

[11] Kang, J. W., Kim, B. S., Chung, M. J. 2008. Development of Assistive Mobile Robots Helping the Disabled Work in a Factory Environment. IEEE/ASME International Conference on Mechatronic and Embedded Systems and Applications, 12-15 Ekim, Beijing, 426431.

[12] Muir, P., Neuman, C. 1987. Kinematic Modeling for Feedback Control of an Omnidirectional Wheeled Mobile Robot. IEEE/ASME International Conference on Mechatronic and Embedded Systems and Applications, 31 Mart-3 Nisan, Raleigh, 1772-1778.

[13] Zhao, D., Deng, X., Yi, J. 2009. Motion and Internal Force Control for Omnidirectional Wheeled Mobile Robots. IEEE/ASME Transactions on Mechatronics, 14(2009), 382-387.

[14] Huang, H. C. 2018. A Hybrid Metaheuristic Embedded System for Intelligent Vehicles Using Hypermutated Firefly Algorithm Optimized Radial Basis Function Neural Network. IEEE Transactions on Industrial Informatics, Erken Erişime Açık Yayın(2018), $1-1$.

[15] Yu, Y., ve di $\breve{g}$. 2017. Self-Paced Operation of a Wheelchair Based on a Hybrid Brain-Computer Interface Combining Motor Imagery and P300 Potential. IEEE Transactions on Neural Systems and Rehabilitation Engineering, 25(2017), 2516-2526.

[16] Tlale, N., Villiers, M. D. 2008. Kinematics and Dynamics Modelling of a Mecanum Wheeled Mobile Platform. 15th International Conference on Mechatronics and Machine Vision in Practice, 2-4 Aralık, Auckland, 657-431.

[17] Chau, K. T., Liu, C. L., Jiang, J. Z. 2008. Comparison of Outer-Rotor Stator-Permanent-Magnet Brushless Motor Drives for Electric Vehicles. International Conference on Electrical Machines and Systems, 17-20 Ekim, Wuhan, 2842-2847.

[18] El-Refaie, A. M., Jahns, T. M. 2005. Optimal Flux Weakening in Surface PM Machines Using FractionalSlot Concentrated Windings. IEEE Transactions on Industry Applications, 41(2005), 790-800.

[19] El-Refaie, A. M., Zhu, Z. Q., Jahns, T. M., Howe, D. 2009. Winding Inductances of Fractional Slot SurfaceMounted Permanent Magnet Brushless Machines. The International Journal for Computation and Mathematics in Electrical and Electronic Engineering, 28(2009), 1590-1606.

[20] Cros, J., Viarouge, P. M. 2002. Synthesis of high performance PM motors with concentrated windings. IEEE Transactions on Energy Conversion, 17(2002), 248-253.

[21] Wiak, S., Krawczyk, A., Dolezel, I. 2008. Advanced computer techniques in applied electromagnetics. Studies in Applied Electromagnetics (Book 30). IOS Press, 472s. 
[22] Lungoci, C. M., Geoergescu, M., Calin, M. D. 2012. Electrical Motor Types for Vehicle Propulsion. 13th International Conference on Optimization of Electrical and Electronic Equipment, 24-26 May1s, Brasov, 635640 .

[23] Carraro, E., Bianchi, N., Zhang, S., Koch, M. 2018. Design and Performance Comparison of Fractional Slot Concentrated Winding Spoke Type Synchronous Motors With Different Slot-Pole Combinations. IEEE Transactions on Industry Applications, 54(2018), 2276-2284.

[24] Hanselman, D. C. 2003. Brushless permanent magnet motor design. 2nd edition, The Writers' Collective,
$392 s$.

[25] Hendershot, J. R., Miller, T. J. E. 2010. Design of brushless permanent-magnet machines. 2nd edition, Motor Design Books LLC, 822s.

[26] Bianchi, N., Bolognani, S., Luise, F. 2005. Analysis and Design of a PM Brushless Motor for High-Speed Operations. IEEE Transactions on Energy Conversion, 20(2005), 629-637.

[27] Ishak, D., Zhu, Z. Q., Howe, D. 2006. Comparison of PM Brushless Motors, Having Either All Teeth or Alternate Teeth Wound. IEEE Transactions on Energy Conversion, 21(2006), 95-103. 